\title{
MODELOS DE DEPÓSITOS MINERAIS
}

B.R. Figueiredo

\section{RESUMO}

Os conceitos atuais utilizados na elaboração de modelos de depósitos minerais (MDM) săo analisados neste estudo com o objetivo de avaliar a aplicaçäo desse conhecimento nas pesquisas metalogenéticas e nas atividades de prospeção mineral no Brasil.

Apesar dos modelos de depósitos constituirem prática antiga e usual em prospeçăo, avanços tecnológicos significativos têm sido obtidos nessa área, a partir dos anos oitenta, nos países desenvolvidos.

Neste estudo foram considerados os modelos descritivo-genéticos, o método DPC de elaboração de modelos integrados, o modelo teor/tonelagem e o de probabilidade de ocorrência. Todos esses modelos possuem, em maior ou menor grau, importantes aplicaçóes em prospecçăo, gestão de recursos minerais, planejamento do uso e ocupaçăo do solo, ensino e pesquisa científica.

Os depósitos de ouro, associados a formaçöes ferriferas, do greenstone belt Rio das Velhas (MG) e os depósitos de chumbo, zinco e prata do Vale do Ribeira (SP e PR) são abordados neste estudo como exemplos de aplicaçăo de modelos descritivo-genéticos.

As relações entre modelos de depósitos minerais "stricto sensu" e os métodos de avaliaçăo do potencial mineral de regiōes são também discutidos a partir da experiência acumulada internacionalmente nos últimos anos.

O desenvolvimento e a aplicaçáo das tecnologias atuais de elaboração de modelos de depósitos minerais no Brasil pode representar um ganho significativo em eficácia e economia de recursos para as empresas de exploração mineral brasileiras e um salto de qualidade na atividade de ensino e pesquisa em geologia econômica.

Departamento de Metalogęnese e Geoquímica, Instituto de Geociências, IG/UNICAMP, Caixa Postal 6152, 13081-970 Campinas, SP. 


\begin{abstract}
Modern concepts of mineral deposit modelling (MDM) are reviewed in this study and their applicability to metallogenetic research and ore prospecting activities in Brazil is critically evaluated. Although ore deposit modelling has long been a common practice in mineral exploration, major advances have taken place in this area due to technological breakthroughs, during the last decade, particularly in developed countries.

Included in the present study are the theoretical background and examples of the descriptive and genetic models, the data-process-criteria method for generating integrated models, the grade/tonnage model and the occurrence probability model. These models are, to a greater or lesser extent, very useful in mineral exploration, mineral resource management, land use planning, education, and scientific research.

Gold deposits related to iron-formation in the Rio das Velhas greenstone belt, Minas Gerais, and the lead, zinc, and silver deposits in the Vale do Ribeira mineral province, São Paulo and Paraná, Brazil, serve as examples of descriptive-genetic models.

The link between mineral deposit modelling and evaluation of regional mineral resource potential is also discussed on the basis of current international experience in these areas.

Recent achievements in MDM can rapidly be incorporated by active professionals both in mining industries and in educational/research centers in Brazil. These new techniques are essential for increasing the effectiveness of mineral exploration and improving the quality of teaching/research activities in economic geology.
\end{abstract}

\title{
INTRODUÇÃo
}

Elaborar um modelo de depósito mineral (MDM) é organizar de algum modo a informação existente sobre os atributos essenciais dos depósitos minerais que pertencem a um mesmo tipo ou a uma mesma classe. Elaboraçăo de modelos de depósitos minerais (mineral deposit modelling), classificação de depósitos minerais, descrição de tipologias, definiçăo de sistemas de formação de depósitos etc, constituem operações equivalentes.

A prática de elaboraçăo de modelos de depósitos minerais é tăo antiga quanto o uso dos metais. O geólogo exploracionista, o prospector leigo, o garimpeiro trabalham sempre com algum modelo de depósito mineral, mais ou menos desenvolvido, em mente.

Um grande avanço tecnológico na elaboraçăo de MDM, entretanto, viria a ocorrer durante os anos 80 , especialmente no que tange ao desenvolvimento de novas metodologias, nas divisóes de geologia econômica, prospeç̧áo mineral e geomatemática dos Serviços Geológicos de países como Estados Unidos, Canadá, Finlândia e outros. Essas novas propostas metodológicas foram condicionadas pelos avanços na informática e pela 
disponibilidade de bancos de dados geológicos e de depósitos minerais, criados nesses países, mais ou menos na mesma época, em meados da década de 70 (ALBERT et al., 1989). Compilaçóes de modelos de depósitos minerais podem ser encontradas em ERICKSSON (1982), ECKSTRAND (1984), USGS-INGEOMINAS (1984), COX \& SINGER (1986), ROBERTS \& SHEAHAN (s.d.) entre outros autores.

Em dezembro de 1986, foi realizado no Brasil um workshop com o objetivo de divulgar as metodologias atuais de elaboração de modelos de depósitos minerais. Organizado pela International Union of Geological Sciences (IUGS), com o apoio da UNESCO e do IBRAM, esse workshop elegeu como objeto de estudo os depósitos auríferos do greenstone belt Rio das Velhas, no Quadrilátero Ferrífero, Minas Gerais.

O objetivo do presente trabalho é o de analisar os principais conceitos que têm embasado a construçăo de modelos de depósitos minerais nos últimos anos, a partir da experiência adquirida no workshop de Belo Horizonte. Um segundo objetivo é o de discutir as aplicaçōes das novas técnicas de MDM no ensino e pesquișa cientifica em metalogênese e nas atividades de prospecção mineral. Este artigo reproduz, quase que integralmente, as aulas sobre o tema que foram proferidas pelo autor na disciplina Metalogênese Global, do Mestrado em Geociências da Unicamp, a partir de 1987.

\section{CLASSIFICAÇÃO DE DEPÓSITOS MINERAIS}

Segundo COX et al. (1986), o estabelecimento de modelos de depósitos minerais corresponde a uma classificagăo de tipos de depósitos. Esses autores sugerem a adoçăo de uma classificação de tipos ou modelos de depósitos minerais (Tabela 1) na qual a ênfase é colocada na litologia das rochas hospedeiras e no posicionamento tectónico do depósito, feiçóes que sâo bastante aparentes ao geólogo durante a preparaçăo dos mapas geológicos. Trata-se portanto de uma classificação muito simples, que se adapta perfeitamente aos depósitos caracterizados como singenéticos mas que oferece problemas para a classificação dos depósitos epigenéticos.

Com base nessa classificaçăo, COX \& SINGER (1986) coordenaram a elaboraçăo de uma longa lista de modelos de depósitos minerais adotando denominaçōes tais como:

- modelo descritivo tipo Bushveld Fe-Ti-V: depósitos relacionados a intrusōes máfico-ultramáficas em ambientes estáveis.

- modelo teor/tonelagem tipo Cu-Au porfirítico: depósitos relacionados a intrusőes félsicas pórfiro-afaníticas.

Modelos como esses, conceituados mais adiante neste trabalho, resultam da compilaçăo exaustiva das feiçóes características de um grande número de depósitos pertencentes ao mesmo tipo. Dessa forma, esses modelos permitem aos ge6logos compararem as suas observaçóes individuais com o conhecimento e a experiência acumulados de um grande número de pesquisadores. 
Evidentemente, os diferentes modelos apresentam graus diversificados de desenvolvimento. Por exemplo, os modelos de depósitos de sulfeto maciço e os de depósitos porfiriticos de Cu-Mo são bem mais desenvolvidos que os modelos de depósitos sedimentares exalativos de $\mathrm{Pb}-\mathrm{Zn}$. Isso porque, quanto maior o número de depósitos conhecidos de um determinado tipo, mais desenvolvido é o modelo de depósito mineral. O modelo do depósito de $\mathrm{Cu}, \mathrm{U}, \mathrm{REE}$, Au e Ag de Olympic Dam, na Austrália, é baseado em um único caso conhecido, portanto constitui um modelo muito pouco desenvolvido (ROBERTS \& HUDSON, 1983).

É fácil perceber que a compilaçăo de modelos de depósitos minerais é extremamente útil aos estudos de avaliação de recursos minerais e aos trabalhos de propecção. São também utilizados como ferramentas indispensáveis no planejamento do uso e ocupaçăo do solo, no ensino de geologia econômica e para identificar problemas fundamentais para a pesquisa científica.

Tabela 1 - Classificaçáo de depósitos minerais segundo o ambiente geológico-tectônico (simplificado de COX et al., 1986).

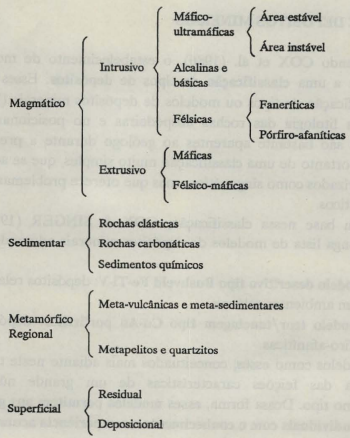




\section{CLASSES DE MODELOS DE DEPÓSITOS MINERAIS}

Existem inúmeras propostas de modelos de depósitos minerais. ADAMS (1985) agrupou as propostas existentes em três classes, a saber:

- modelos empíricos, descritivos ou de ocorrência: estruturais, geoquímicos, de zoneamento, de alteraçăo, geofísicos, cristaloquímicos, teor/tonelagem, etc.

- modelos conceituais, genéticos ou de processos: estruturais, geoquímicos, de zoneamento, de alteração, geofísicos, cristaloquímicos, etc.

- modelos metodológicos, diagnósticos ou integrados: modelos de exploração, método DPC (data-process-criteria), de hipoteses de trabalho múltiplas, etc.

Para os objetivos do presente estudo, săo comentados, a seguir, os modelos descritivo e genético, o método DPC de elaboraçăo de modelos integrados, os modelos teor/tonelagem e de probabilidade de ocorrência.

Em geral, os modelos descritivos existentes ainda são bastante incompletos e os modelos genéticos excessivamente especulativos. Com essa constataçăo, BARTON (1986) advoga que os modelos, mesmo os incipientemente desenvolvidos, abrem caminho para testes rigorosos de campo e de laboratório, que, muitas vezes, contribuem para derrubar dogmas de há muito estabelecidos na geologia econômica, como por exemplo:

- os estudos de inclusōes fluidas mostraram conclusivamente que os depósitos do tipo Mississipi Valley năo podem ter se formado nem a partir de processos singenéticos nem de águas superficiais inalteradas;

- os estudos de isótopos estáveis provaram que os depósitos epitermais de metais base e preciosos se formaram a partir de águas meteóricas que circularam em sistemas geotermais fósseis.

\section{MODELOS DESCRITIVOS E GENÉTICOS}

O modelo descritivo de depósitos minerais compreende a listagem dos atributos reconhecidos como diagnósticos ou essenciais de um tipo de depósito mesmo que as relaçōes entre esses atributos sejam desconhecidas. Em um modelo genético, os atributos essenciais ao tipo de depósito sấo interrelacionados através de algum conceito teórico. $\mathrm{Na}$ realidade, sempre é usada alguma hipótese genética, ainda que pouco desenvolvida, para permitir o agrupamento de vários depósitos em um único tipo e para diminuir o número de critérios ou atributos que definem o tipo de depósito.

Na Tabela 2 é sugerida uma planilha para a descrição dos depósitos minerais usando-se como exercício a jazida de ouro do Morro Velho, Minas Gerais. Descriçōes semelhantes a essa foram elaboradas pelos participantes do workshop de Belo Horizonte também para as jazidas de ouro do Cuiabá, São Bento e Passagem, todas situadas no greenstone belt Rio das Velhas, Minas Gerais. Com base nas descriçōes individuais desses 
Tabela 2 - Ficha para descriçōes individuais de depósitos minerais (adaptado de THORMAN, pes.com., 1986).

Tịpo de depósito: Depósito de ouro em formação ferrífera

Nome: MORRO VELHO

Toponimia: nenhuma

Municipio/Estado/País: Nova Lima, Minas Gerais, Brasil

Latitude/longitude: $19^{\circ} 58^{\prime} 48^{\prime \prime} \mathrm{S}, 43^{\circ} 50^{\prime} 56^{\prime \prime} \mathrm{W}$

Bem mineral: ouro e prata como subproduto, produçăo de ácido sulfúrico e arsênico no passado.

Produção passada: 273,2 t (1834-1978).

Descrição do depósito: o ouro ocorre na formação ferrífera carbonática denominada Formaçáo Lapa Seca; vários corpos mineralizados dispōem-se ao longo de zonas lineares extensas com plunges de grande amplitude; o depósito foi submetido a períodos múltiplos de dobramento e a metamorfismo do fáceis xisto verde baixo a médio.

Tipos de rochas: Supergrupo Rio das Velhas/Grupo Nova Lima: rochas vulcânicas máficas, intermediárias e félsicas; Formação Lapa Seca: formaçáo ferrífera carbonática, metapelitos e filito grafitoso.

Texturas: cristaloblástica, xistosa e, localmente, lineação bem desenvolvida.

Litologia da hospedeira: Formaçâo Lapa Seca: rocha ferro-carbonática com quartzo, sericita, grafita, feldspato, lentes de sulfetos e intercalaçōes de metatufos intermediários a félsicos.

Nome da rocha hospedeira: Formação Lapa seca.

Idade da rocha hospedeira: Arqueana: $2,7 \mathrm{Ga}(\mathrm{Rb} / \mathrm{Sr})$.

Idade da mineralizaçāo: Arqueana (?): 2,7-2,8 Ga (galena).

Ambiência tectônica/deposicional durante a formação da rocha hospedeira: sedimentação química em período de quiescência da atividade vulcânica.

Ambiência tectônica durante a mineralização: estabilidade tectônica.

Rochas ígneas associadas \# Idade das igneas associadas \# Minerais de minério \# Mineralogia \# Minerais de alteraçāo \# Textura/estrutura do minério \# Controles da mineralização \# Assinatura geoquímica/concentraçōes de metais \# Alteração supéngena \# Depósitos minerais associados \# Comentários \# Referências. 
depósitos e nas informaçóes reunidas sobre as jazidas de ouro de Homestake (USA) e de Lupin (Canada), THORMAN (pes.com.,1986) organizou a Tabela 3, na qual alguns dos atributos desses depósitos são tentativamente caracterizados como diagnósticos ou permissivos, de acordo com a freqüência (alta ou baixa, respectivamente) com que aparecem nas descriçöes dos depósitos.

Como resultado desse exercício, os seis depósitos aurfferos estudados se agruparam básicamente em dois tipos: singenético, com pouca ou nenhuma mobilizaçáo do ouro (Morro Velho, Homestake e Lupin) e epigenético, com o controle principal da mineralizaçăo devido à deformação (Passagem e São Bento). A jazida de Cuiabá ocuparia uma posiçăo intermediária no tipo singenético com mobilizaçăo moderada do ouro devido a eventos posteriores.

As informaçóes sobre as jazidas incluidas no exercício anterior săo largamente baseadas nos trabalhos publicados que devem ser referenciados no ultimo ítem da planilha de descriçăo dos depósitos. A listagem dos critérios diagnósticos de um grupo de depósitos considerados como de uma mesma filiaçáo genética representa o modelo descritivo desse tipo.

A compreensão mais profunda da interrelação entre os critérios diagnósticos pode subsidiar a elaboração do modelo genético. Tome-se como exemplo a formulação abaixo sobre a formação do tipo Morro Velho, conforme foi discutido no workshop de Belo Horizonte e resumido por THORMAN (pes.com., 1986):

"...as questōes mais importantes têm a ver com o ambiente deposicional da Formação Lapa Seca, a sua arquitetura litológica e história de alteraçăo hidrotermal que conduziu à mineralizaçăo final. Qual é a relaçăo estratigráfica entre a rocha carbonática e as várias intercalações de rocha metatufácea, metapelitos, filitos etc? Quais foram os protolitos dessas rochas, especialmente das rochas carbonáticas, e em particular dos fáceis carbonáticos maciços e bandados? A idade dos metariolitos que se sobrepóem à Lapa Seca precisa ser determinada. A fonte de Pt e Pd deve ter tido uma importante relaçäo com os fluidos mineralizantes a ouro."

"...muitos geólogos parecem concordar que o depósito é stratabound e estratiforme, porém alguns năo concordam com a interpretaçăo de depósito singenético para Morro Velho, principalmente devido a quantidade considerável de alteração que ocorreu na Formaçăo Lapa Seca e ao fato de que os corpos minerais apresentam uma alta coincidência com os eixos das dobras."

"...tanto para Morro Velho como para Homestake, a maioria das evidencias favorece fortemente uma origem singenética, mas uma linha de argumentaçăo igualmente forte indica um controle estrutural para o depósito."

Como foi mencionado antes, a tentativa de elaboraçăo de modelos genéticos esbarra na insuficiência de informaçōes geologicas e sugere questōes novas para a pesquisa científica. No caso da jazida de Morro Velho, apesar de ter sido objeto de vários estudos, entre os quais LADEIRA (1980), algumas questōes chave para o entendimento da gênese do 
Tabela 3 - Alguns critérios para depósitos auríferos do greenstone belt Rio das Velhas e depósitos associados: $\mathbf{S}=$ atributo presente, provável critério diagnóstico do tipo singenético ou epigenético, $\mathbf{P}=$ provável critério permissivo, $\mathbf{P} / \mathbf{S}=$ posiçăo incerta e $\mathbf{X}=$ atributo ausente no depósito (modificado de THORMAN, pes.com., 1986).

Critérios

Greenstone belt

BIF tipo Algoma

Fáceis oxido

Fáceis carbonato

Chert

Fáceis sulfetada

Filito grafitoso

Qz-sericita xisto

Vulcânicas máficas

Stratabound

Estratiforme

Fáceis xisto verde

Pirita

Pirrotita

Arsenopirita

Turmalina

Scheelita

Carbonatos(alteraçāo)

Controle estrutural

Morro Cuiabá
Velho

Såo Passagem Bento

\begin{tabular}{|c|c|c|c|c|c|}
\hline $\mathbf{S}$ & $\mathrm{s}$ & $\mathbf{S}$ & $\mathrm{S}$ & $\mathbf{S}$ & $\mathrm{s}$ \\
\hline $\mathbf{S}$ & $\mathbf{S}$ & $\mathbf{S}$ & $\mathbf{P}$ & $\mathrm{S}$ & $\mathrm{S}$ \\
\hline $\mathrm{X}$ & $\mathrm{X}$ & $\mathrm{s}$ & $\mathrm{X}$ & $\mathrm{X}$ & $\mathrm{X}$ \\
\hline $\mathbf{S}$ & $s$ & $\mathbf{S}$ & $\mathbf{P}$ & $\mathrm{X}$ & $\mathrm{S}$ \\
\hline $\mathbf{P}$ & $\mathbf{P}$ & $\mathbf{P}$ & P & $\mathbf{P}$ & P \\
\hline $\mathbf{S}$ & $\mathbf{S}$ & $\mathbf{X}$ & X & $\mathrm{S}$ & $\mathrm{S}$ \\
\hline $\mathbf{P}$ & $\mathbf{P}$ & $\mathbf{P}$ & $\mathbf{P}$ & $\mathrm{P}$ & $P$ \\
\hline $\mathrm{P} / \mathrm{S}$ & $\mathrm{P} / \mathrm{S}$ & $\mathbf{P} / \mathrm{S}$ & $\mathrm{P} / \mathrm{S}$ & X & $\mathrm{X}$ \\
\hline $\mathrm{P} / \mathrm{S}$ & $\mathrm{P} / \mathrm{S}$ & $\mathrm{P} / \mathrm{S}$ & $\mathrm{X}$ & $\mathrm{X}$ & P \\
\hline $\mathbf{s}$ & $\mathrm{s}$ & $\mathrm{s}$ & $\mathrm{P} / \mathrm{S}$ & $\mathrm{s}$ & $\mathrm{s}$ \\
\hline $\mathrm{S}$ & $\mathbf{S}$ & $\mathbf{X}$ & X & $\mathrm{S}$ & $\mathrm{S}$ \\
\hline $\mathbf{S}$ & $\mathrm{S}$ & $\mathbf{S}$ & $\mathrm{s}$ & $\mathrm{S}$ & $\mathrm{S}$ \\
\hline$P / S$ & $\mathrm{~S}$ & $\mathrm{P} / \mathrm{S}$ & $\mathrm{P} / \mathrm{S}$ & $\mathbf{P}$ & P \\
\hline $\mathrm{s}$ & $\mathrm{P} / \mathrm{S}$ & $\mathrm{P} / \mathrm{S}$ & $\mathrm{P} / \mathrm{S}$ & $\mathrm{S}$ & $\mathrm{S}$ \\
\hline$P / S$ & $\mathbf{P}$ & $\mathbf{S}$ & $\mathrm{S}$ & P & $\mathbf{P}$ \\
\hline $\mathbf{P}$ & $\mathbf{P}$ & $\mathbf{P}$ & $\mathbf{P}$ & $\mathrm{X}$ & $\mathrm{X}$ \\
\hline $\mathrm{P} / \mathrm{S}$ & $\mathbf{P}$ & $\mathbf{S}$ & $\mathrm{S}$ & P & $\mathrm{P}$ \\
\hline $\mathbf{P}$ & $\mathbf{P}$ & $\mathbf{P}$ & $\mathbf{S}$ & $\mathrm{X}$ & $\mathrm{X}$ \\
\hline $\mathbf{F}$ & P & $\mathbf{S}$ & $\mathrm{S}$ & $\mathbf{F}$ & $P$ \\
\hline
\end{tabular}


depósito ainda precisam ser pesquisadas antes que se possa elaborar um modelo genético consistente para esse tipo de depósito.

Um segundo exercício de elaboraçăo de modelos descritivos e genéticos foi realizado pelos alunos da área de metalogênese do IG-Unicamp com a assessoria do geólogo Cássio R. Silva (CPRM, São Paulo) em 1988. Com base na literatura (FLEISCHER, 1976; SILVA et al., 1982; DAITX et al., 1983; MACEDO, 1986), os depósitos Pb-Zn-Ag do Vale do Ribeira podem ser agrupados em dois modelos ou tipos de depósitos: o Perau e o Panelas. Descriçóes individuais de duas jazidas pertencentes a esses modelos estão resumidas na Tabela 4 e alguns critérios diagnósticos do tipo Perau estão listados na Tabela 5.

As propostas de caracterizaçáo genética atribuidas a esses dois tipos de depositos, sedimentar exalativo para o tipo Perau e epigenético para o tipo Panelas, vêm sendo confirmadas pelos estudos mais recentes. TASSINARI et al. (1990) demonstraram que as mineralizaçōes das jazidas agrupadas nos tipos Perau e Panelas possuem assinaturas isotópicas $\mathrm{de} \mathrm{Pb}$ e $\mathrm{Sr}$ bastante distintas.

Outros trabalhos contendo propostas de modelos descritivos e genéticos podem ser encontrados, entre outros, em SILVA (1985) para os depósitos brasileiros de $\mathrm{Pb}, \mathrm{Zn}$ e F; em ROIG (1990) para os depósitos de Pb e Zn do tipo Mississipi Valley; e em CABRAL Jr. (1991) para os depósitos sedimentares fosfáticos, evaporíticos e de metais base da Bacia do Paraná (SP).

\section{O MÉTODO DPC (DATA-PROCESS-CRITERIA)}

Em uma abordagem superficial, os critérios diagnósticos que definem um tipo de depósito săo aqueles atributos que se repetem em um grande número de casos.

Um método um pouco mais sofisticado de identificaçăo dos critérios diagnósticos de tipos de depósitos minerais foi proposto por ADAMS (1985) - o método DPC. A virtude desse método, como se verá adiante, é o de induzir os geblogos a raciocinar sobre os processos que podem ter sido responsáveis pela presença desta ou daquela feiçăo identificada.

A identificaçao dos critérios diagnósticos de um determinado tipo de depósito, através do método DPC, envolve uma estimativa do grau de necessidade e suficiência das características inventariadas desses depósitos.

Ao lado de uma lista de depósitos análogos (mesmo tipo) e dos dados geológicos que caracterizam esses depósitos, deve ainda ser elaborada uma lista de processos que podem ter sido responsáveis pelas características desses depositos.

Uma evidencia é necessária quando as características são sempre formadas pelo processo: se as características estáo presentes, isso indica que o processo ocorreu, e se estão ausentes, isso indica que o processo não ocorreu.

Quando as características são formadas pelo processo em questão, mas podem também ser formadas por outros processos, essas características são necessárias mas não constituem evidencia suficiente de que esse processo particular tenha operado. 
Tabela 4 - Descriçōes individuais de jazidas de $\mathrm{Pb}-\mathrm{Zn}$ - $\mathrm{Ag}$ representativas dos tipos Perau e Panelas no Vale do Ribeira.

Tipo Perau

Mina do Perau, Adrianópolis, PR

Tipo: estratiforme/stratabound

Reserva: $1,9 \mathrm{Mt}: 4 \% \mathrm{~Pb}, 2 \% \mathrm{Zn}$ e $85 \mathrm{~g} / \mathrm{t} \mathrm{Ag}$ 830000 t: $2 \% \mathrm{Cu}$

Rochas: rochas carbonaticas impuras (calcio-silicáticas, meta-calcáreos, metadolomitos), intercalaçóes de filito grafitoso e barita, BIF no topo. Sobrepōem quartzitos e săo sotopostas por mica xistos e anfibolitos. Fm Perau, Grupo Setuva.

Idade: Proterozóico Médio

$$
1,7-1,5 \mathrm{Ga} \text {. }
$$

Amb.tectônico: estrutura intra-plataformal do tipo aulacógeno.

Forma: bolsōes ao longo de eixos de dobras regionais, dimensōes variáveis dentro do horizonte mineralizado.

Mineralogia: galena, pirita, calcopirita, esfalerita (pirrotita, tetraedrita, covelita, arsenopirita, estanita, calcosita), calcita, quartzo, fluorita.

Comentario: deposito singenético do tipo sedimentar exalativo.
Tipo Panelas

Mina do Rocha, Adrianópolis, PR

filonar em fraturas e falhas

epicalcários dolomíticos com intercalaçōes de filitos e calcio-xistos com clorita e quartzo. Fm Votuverava, Grupo Açungui.

Proterozóico Médio

$1,4-1,1 \mathrm{Ga}$.

estrutura rift, deposição em ambiente plataformal marinho de águas rasas.

filonares com direçäo predominante NNWSSE, discordantes da direçáo das camadas.

galena, pirita, calcopirita, esfalerita, pirrotita, marcassita, cerusita, smithsonita, piromorfita, goetita, barita.

mineralizaçáo epigenética devido à remobilizaçăo de metais contidos nas rochas metassedimentares e do embasamento. 
Tabela 5 - Alguns critérios diagnósticos para os depósitos de $\mathrm{Pb}-\mathrm{Zn}$-Ag do tipo Perau baseado em FLEISCHER (1976), SILVA et al. (1982), DAITX et al. (1983), CHIODI F (1984), MACEDO (1986) e TASSINARI et al. (1990).

\footnotetext{
\# Estratiforme/stratabound, concordante com as rochas encaixantes.

\# Posiçăo estratigráfica definida, a mesma em diversos depósitos.

* Associaçăo com formaçбes ferriferas e niveis de barita.

* Rochas vulcánicas básicas presentes na área.

\# Idades 1,7-1,5 Ga bem diferente e superior a dos depósitos epigenéticos tipo Panelas.

\# Predominancia de sulfetos de $\mathrm{Pb}$ e Fe sobre os de $\mathrm{Cu}$ e $\mathrm{Zn}$.

* Predominância de Ag sobre Au. calcita.

\# $\left({ }^{206} \mathrm{~Pb} / 204 \mathrm{~Pb}\right)=16,157-16,505 \mathrm{em}$ galena; $\left({ }^{87} \mathrm{Sr} /{ }^{86} \mathrm{Sr}\right) \mathrm{i}=0,705-0,706 \mathrm{em}$ barita e

\# Mineralizaçáo lenticular com partes maciças com mais de $50 \%$ de sulfetos.

\# Ocorrencia de estruturas de deslizamento na mineralizaçáo.

\# Mineralização em bacia tafrogenica, sumetida à tectônica tracional comum à jazidas exalativas sedimentares.
}

A estimativa do grau de necessidade e de suficiência pode ser feita, segundo ADAMS (1985), através da aplicaçāo das seguintes regras:

- se a característica é formada por ou associada ao processo, a necessidade é alta, se a feiçăo ocorre comumente ou consistentemente, intermediária, se aparece em alguns casos e baixa se ocorre apenas raramente;

- se a característica é produzida somente pelo processo, não existem processos alternativos plausíveis, e reflete aspectos significantes do processo, a suficiência é alta, intermediária ou baixa se também ocorre, respectivamente, em quase todos os casos, em alguns ou raramente.

Para que uma característica seja listada como critério diagnóstico impōe-se que ela alcance pelo menos um grau alto de necessidade ou suficiência. Se isso năo ocorrer, a característica é listada como critério permissivo.

O método de Adams promove hipóteses múltiplas de trabalho e leva em conta todos os dados relevantes existentes sobre os depósitos numa tentativa de corrigir a tendência natural do geólogo de construir modelos negligenciando os testes de consistência dos mesmos.

Um modelo de exploraçäo deve incluir os critérios de mais alto grau de necessidade e suficiência possível para cada processo de formação de depósito, ou seja, ele contém o mínimo de critérios diagnósticos em funçăo dos quais a exploração mineral será requerida visando a avaliação da favorabilidade de uma área para um determinado tipo de depósito. 


\section{MODELO TEOR/TONELAGEM}

O modelo teor/tonelagem é apresentado em forma de gráfico com o objetivo de facilitar a comparaçăo entre os diferentes tipos de depósitos. As fontes dos dados de teores e tonelagens săo a literatura e os bancos de dados de recursos minerais.

Nesses gráficos, os logarítmos dos teores ou das tonelagens de todos os depósitos conhecidos de um determinado tipo, em bases mundiais, săo plotados nas abcissas e as proporçő́es acumuladas do número de depósitos săo plotadas nas ordenadas (Fig. 1). Para maior confiança nesses modelos, recomenda-se que cerca da metade do número dos depósitos seja maior e a outra metade seja menor que as medianas do teor e da tonelagem.

Na Figura 1a estão plotados as tonelagens de 118 depósitos de ouro do tipo veios de quartzo com sulfetos (COX \& SINGER, 1986). A partir desse gráfico, e assumindo que a distribuiçăo é lognormal, é possível estimar que a probabilidade de encontrar depósitos desse tipo com mais de 41000 té de $50 \%$, com mais de $1,3 \mathrm{Mt}$ é de $10 \%$ e assim por diante.
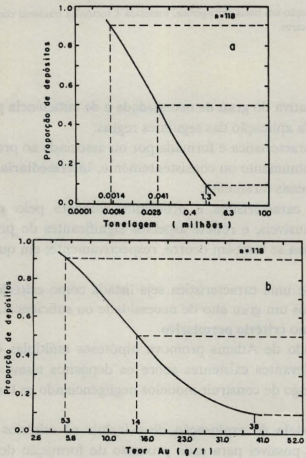

Figura 1 - Modelos teor/tonelagem para 118 depósitos de ouro em veios de quartzo com sulfetos (COX \& SINGER, 1986). 
Na Figura 1b estăo plotadas os teores dos mesmos depósitos de ouro. Com um raciocínio análogo é possível estimar que a probabilidade de encontrar depósitos desse tipo com teores superiores a $14 \mathrm{~g} / \mathrm{t}$ é de $50 \%$, superiores a $38 \mathrm{~g} / \mathrm{t}$ é de $10 \%$ e assim por diante.

Esses modelos, evidentemente, devem ser usados com cautela, especialmente quando o número de casos descritos é pequeno.

\section{MODELO DE PROBABILIDADE DE OCORRÊNCIA}

A elaboraçáo de modelos geológicos determinísticos, que é orientada para a identificação de regiōes que dupliquem ao máximo as características metalogenéticas de regióes portadoras de jazidas minerais, representa a essência do raciocínio dos geólogos exploracionistas convencionais. Por mais sofisticadas que sejam as metodologias utilizadas nessas comparaçōes continuarão existindo todavia duas dificuldades incontornáveis pelos geólogos. Segundo AGTERBERG (1981), uma ou mais feiçóes importantes dos metalotectos podem não ter sido ainda percebidas pelos geblogos devido o estágio atual do conhecimento e, por outro lado, uma ou mais jazidas minerais importantes podem ainda năo terem sido descobertas na área modelo, resultando numa subestimaçăo do seu potencial mineral.

A abordagem quantitativa na avaliação do potencial mineral de regiōes, através do processamento de um grande número de variáveis disponf́veis e do teste automatizado de diversos modelos de distribuiçăo de depósitos, atenua as limitaçóes inerentes às comparaçóes manuais entre ambientes geológico-tectônicos para fins de propeçắo.

Propostas de modelos quantitativos para avaliaçáo do potencial mineral de regióes encontram-se descritas numa vasta literatura, produzida especialmente nos últimos dez anos (MERRIAN, 1981; HARRIS, 1984; GÁAL \& MERRIAN, 1990). Entre essas propostas merece ser citada a experiência do Serviço Geológico Finlandês de elaboração de modelos de probabilidade de ocorrência.

Resumidamente, os modelos de probabilidade de ocorrencia visam a obtenção de mapas com a localizaçăo das áreas mais favoráveis para a descoberta de novas jazidas minerais de um determinado tipo e bem mineral de interesse.

Comumente, a regiāo pesquisada é dividida em células cujo número e dimensōes devem ser determinados em funçáo da área total e da intensidade de conhecimento geológico alcançado na região. Na Figura 2a está representada uma área de $17850 \mathrm{~km}^{2} \mathrm{da}$ Lapônia Central, norte da Finlândia, que foi estudada por GÁAL (1984). Essa área foi dividida em 732 células com dimensōes $5 \times 5 \mathrm{~km}^{2}$, aproximadamente identicas às folhas topograficas 1:10000 da Finlândia. Cada célula foi definida através da combinaçáo de 58 variáveis: geologicas (litologias e estruturas), geoquímicas (amostras de tilito para 17 elementos), geofísicas (levantamentos aeromagnético e gravimétrico) e de mineralizações (depósitos, indícios e blocos mineralizados).

Nesse estudo particular, o método estatístico escolhido foi a análise 
característica e o programa utilizado foi o NCHARAN, desenvolvido no Serviço Geológico da Noruega. Segundo esse procedimento, as variáveis săo transformados em binários: +1 , se presente e -1 , se ausente para cada célula.

Previamente são processadas as células modelo ou de referência que podem ser definidas internamente ou externamente. As células modelo definidas internamente são aquelas que contêm depósitos conhecidos do tipo e bem mineral de interesse. Quando essa condiçăo năo se cumpre, faz-se então necessário selecionar variáveis a partir de outros ambientes geológico-tectônicos portadores de jazidas e definir, na regiáo, ds células que dupliquem ao máximo essas características.

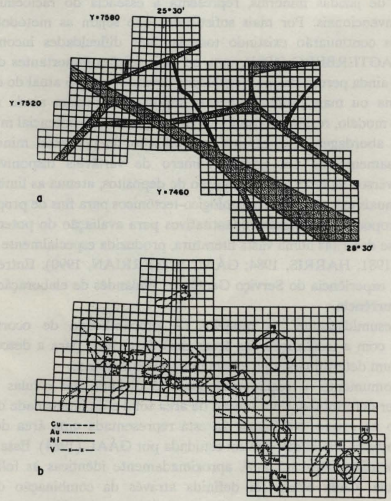

Figura 2 - Modelo de probabilidade de ocorrência: a) área estudada na Lapônia central, Finlândia, divididas em células de $5 \times 5 \mathrm{~km}^{2}$ e áreas pontilhadas indicando zonas de falhas e de cizalhamento; b) mapa de probabilidade de ocorrencia, calculada para $\mathrm{Cu}, \mathrm{Au}, \mathrm{Ni}$ e V (modificado de GÁAL, 1984). 
Em seguida, é calculado o grau de associação entre o conjunto de células da área e as células modelo. Esse grau de associação é expresso em índices de favorabilidade que săo agrupados em várias classes correspondendo a níveis de probabilidade. Se as células com índices mais altos se agrupam, isso pode indicar a coerência do modelo utilizado. Essas áreas devem então ser revisitadas para detalhamento e os controles metalogenéticos devem ser melhor pesquisados antes de recomendar-se a intensificação dos trabalhos exploratórios.

$\mathrm{Na}$ Figura $2 \mathrm{~b}$ estão representadas as áreas metalogenéticas mais prováveis para $\mathrm{Cu}, \mathrm{V}, \mathrm{Au}$ e $\mathrm{Ni}$, as quais representam menos de $10 \%$ da regiăo pesquisada. A faixa mais interessante para $\mathrm{Cu}, \mathrm{V}$ e Au segue uma direçăo NW com 10-20 km de largura e $215 \mathrm{~km}$ de extensăo e parece estar controlada por uma estrutura regional importante representada pela falha Kittila-Salla. Na remobilizaçäo do ouro também deve ter jogado um papel importante o complexo granitóide da Lapônia Central mais ao sul. Por outro lado, as áreas favoráveis para depósitos de níquel parecem estar associadas a uma direção estrutural NE-SW coincidente com a direçăo dos contatos litológicos nos greenstone belts situados na parte leste da região estudada.

Atualmente, os procedimentos para a aplicaçăo de modelos de probabilidade de ocorrência vêm se tornando mais acessiveis graças ao desenvolvimento dos sistemas georeferenciados de informaçőes (SGI) como demonstram as experiências em curso no Laboratório de Processamento de Imagens (LAPIG) da Unicamp (CROSTA, pes.com.,1992) e em outros centros de pesquisa no exterior (WADGE, 1992).

Entretanto, vale notar que uma grande atenção deve ser dada aos aspectos mais críticos da elaboraçăo dos modelos de probabilidade de ocorrência que são a seleção, definiçăo e ponderaçăo das variáveis utilizadas e a análise de consistência que é requerida tanto para a escolha das células modelo como para a apresentaçăo dos mapas metalogenéticos probabilísticos. Parece aconselhável que os geólogos exploracionistas elaborem os seus modelos descritivo-genéticos e de teor/tonelagem, para o tipo de depósito e bem mineral de interesse, antes de partir para a tarefa mais complexa de aplicação de modelos probabilísticos. A seqủencia recomendada para a elaboraçăo de modelos é mostrada na Figura 3.

CHUNG et al. (1992) estabeleceram uma relação quantitativa entre modelos de depósitos minerais "stricto sensu", mapeamento geológico e propecção e demonstraram que um atributo diagnóstico (necessário) de um determinado tipo de depósito, reconhecível nas proximidades do corpo mineral, pode nâo ser diagnóstico (suficiente) para áreas com alta potencialidade para novos depósitos do mesmo tipo. Dessa forma, esses autores fazem a distinçăo entre os critérios diagnósticos que discriminam áreas mineralizadas de áreas estéreis e aqueles que servem para caracterizar tipos de depósitos.

Aparentemente, esses autores năo levaram em conta o caráter dinâmico dos modelos de depósitos minerais, os quais vão se aprimorando e ganhando em robustez a cada novo depósito descoberto do mesmo tipo. Através dos modelos de probabilidade de ocorrência é possfvel listar as variáveis (geológicas, geoquímicas, geofísicas, etc.) que contribuem com maior peso para a seleçăo das áreas mais favoráveis. Obviamente que essas características ou variáveis devem ser incorporadas aos modelos descritivo-genéticos desses depósitos minerais. 


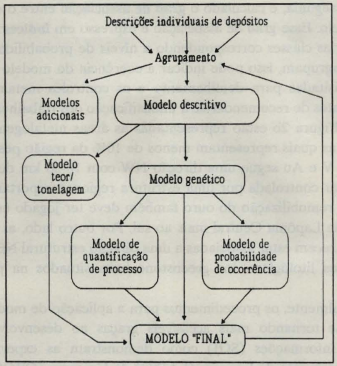

Figura 3 - Fluxograma de evolução dos diferentes tipos de modelos de depósitos minerais (COX et al., 1986).

\section{IMPORTÂNCIA DOS MODELOS DE DEPÓSITOS MINERAIS}

As propostas atuais de elaboração de modelos de depósitos minerais săo fortemente condicionadas pelos rápidos progressos na área de informática. Nesse novo padrăo tecnológico, ao qual a geologia economica vem se adaptando, o dado geológico só tem sentido se organizado de forma a permitir o seu processamento e a sua conversão em informação geológica, verificável, comparável e quantificável, se possível.

A sistematização da informação geológica sobre os depósitos minerais brasileiros ainda está por ser feita. Essa sistematizaçáo além de ser útil para elevar o nível das pesquisas em metalogênese, é também indispensável para aumentar a eficácia dos métodos exploracionistas utilizados pelas empresas.

Para a prospecçáo os modelos mais úteis são o descritivo, genético, teor/tonelagem e de probabilidade de ocorrência. Os estudos quantitativos sobre a potencialidade mineral de regiōes săo também importantes para fins de previsão de suprimento e planejamento do uso e ocupaçāo do solo. Raciocinando ao contrário, o modelo de probabilidade de ocorrência oferece para a indústria mineral uma base científica segura e rápida para o descarte de áreas. 
Para o ensino os modelos considerados mais importantes são o genético e o de quantificaçăo de processos (cinética de reaçóes, transferência de calor e de massa, transporte de fluidos, etc.).

Finalmente, todos os modelos são úteis para orientar a pesquisa científica com destaque para o genético, teor/tonelagem e de quantificação de processos. Para as empresas de mineração que venham a investir na elaboraçăo de modelos descritivo-genéticos, a descoberta de lacunas no conhecimento dos diferentes tipos de depósitos pode oferecer uma variedade inesgotável de temas para a colaboraçăo com as universidades.

\section{CONCLUSŌES}

As tecnologias de MDM constituem ferramentas poderosas para a exploração mineral, metalogênese, gerenciamento de recursos minerais, planejamento do uso e ocupaçáo do solo e outras especialidades das geociências aplicadas. Elas representam uma atualizaçăo dos velhos fundamentos da geologia econômica no contexto da nova realidade que os rápidos avanços na micro-eletrônica e informática vêm ensejando para as práticas cientificas. Entre esses avanços devem ser citados a fabricação de estaçōes de trabalho cada dia mais acessíveis e a difusão de softwares poderosos e amigáveis para o processamento digital de imagens e gerenciamento de variáveis georeferenciadas (SGI: $\mathbf{s}$ ).

A elaboraçăo de modelos de depósitos minerais surge inicialmente nos países desenvolvidos năo apenas porque neles o acesso às facilidades computacionais sempre foi mais rápido e a manutençăo de bancos de dados geológicos sempre foi encarada como uma prioridade, mas também porque aí as fontes de suprimento de recursos minerais estão em vias de esgotamento, os problemas ambientais são criticos e as técnicas convencionais de exploraçăo mineral tornaram-se insatisfatórias.

No Brasil e em outros países produtores de minério do Terceiro Mundo as pressōes na área de exploração mineral são menores e os métodos convencionais de prospecçāo ainda podem dar resultados, especialmente nas regiōes pouco conhecidas geologicamente. Nesses casos, o acesso às inovaçöes na área de informática tem sido mais demorado e os bancos de dados geologicos se organizaram tardiamente e com vários tipos de deficiências.

Năo obstante essa defasagem técnica, o uso de modelos de depósitos minerais é altamente recomendável no Brasil porque através deles, a experiência internacional acumulada passa a ser tomada como referência para a descrição dos depósitos minerais brasileiros. As peculiaridades dos distritos minerais brasileiros podem se tornar mais nítidas, novos modelos podem ser propostos e, com a inclusáo de novas descrições individuais, os modelos já propostos podem ganhar em robustez.

Existem inúmeras propostas de classificaçăo de depósitos minerais à disposição dos geólogos. Neste trabalho é dado apenas um exemplo visando salientar um 
aspecto metodológico que deve ser levado em conta na escolha de classificações de depósitos minerais. As mais úteis são aquelas que se baseiam nos atributos mais aparentes aos geólogos de campo e que se caracterizam como predominantemente descritivas. As classificaçóes genéticas, por incluirem interpretaçóes permanentemente sujeitas a controvérsia, devem ser evitadas. Nos modelos descritivo-genéticos as propostas relativas à origem e evoluçáo do depósito devem constar como comentários, sempre referidos a seus autores, e sujeitos à atualização periódica.

A elaboração de modelos de depósitos minerais no Brasil não deve ser desencorajada pela desconfiança, que muitas vezes procede, sobre a falta de qualidade dos dados geológicos que foram gerados nos projetos do passado. As técnicas de MDM servirão também para testar a qualidade desses dados e estimar o grau de confiabilidade dos mesmos. O reaproveitamento da informação já reunida numa regiāo deve inclusive anteceder e orientar a programação de novos estudos de campo e de laboratório promovendo dessa forma economia de tempo e de recursos.

A inexperiencia na elaboraçăo de modelos e na definiçăo de tipologias de depósitos pode muitas vezes conduzir os geólogos por um raciocínio demasiado formalista e pragmático de superestimaçāo dos próprios modelos, prenúncio de grandes insucessos nas etapas seguintes da exploração mineral. Para diminuir os riscos de insucesso é importante que se tenha presente as limitações inerentes aos vários tipos de modelos.

$\mathrm{Na}$ aplicaçăo dos modelos descritivo-genéticos muitas vezes não é dada a devida importância para as relaçóes espaciais e temporais entre os vários tipos de depósitos presentes na mesma unidade geológico-tectônica. Por outro lado, na elaboração dos modelos de probabilidade de ocorrencia muitas vezes năo săo enfatizados os aspectos genéticos e evolutivos dos depósitos minerais.

Os impactos provocados a cada dia pelas novas interpretações sobre a evolução tectônica dos continentes, especialmente no pré-cambriano, e pelas novas interpretações sobre a gênese dos depósitos minerais, especialmente a partir dos estudos isotópicos e de inclusōes fluidas, por si sós já justificariam considerar os modelos de depósitos minerais como sistematizaçóes incompletas e passíveis de aperfeiçoamento contínuo.

O aprimoramento das técnicas de elaboração de modelos de depósitos minerais tem demandado uma intensificaçăo nas pesquisas metodológicas nas áreas de análise de recursos minerais, geomatemática, bancos de dados, processamento digital de imagens, SGIs etc. Entretanto, para que essas técnicas venham a representar uma contribuiçáo efetiva para a exploraçáo mineral torna-se imprescindível contar com os resultados de pesquisa convencional obtidos nas áreas de estudos tectónicos e metalogenéticos regionais e de gênese e evoluçăo de depósitos minerais. De onde se conclui que o uso de técnicas não convencionais em geologia econômica ao mesmo tempo estimula e se alimenta dos resultados de pesquisa obtidos através das técnicas convencionais. 


\section{AGRADECIMENTOS}

Agradeço aos coordenadores e participantes do Workshop on Mineral Deposit Modelling, Belo Horizonte, 1986, na pessoa do Prof. Eduardo A. Ladeira, bem como aos alunos do mestrado em Metalogênese da Unicamp pelas interessantes discussōes que motivaram a elaboraçăo deste trabalho. Aos professores do IG/Unicamp, Roberto P. Xavier e Álvaro P. Crosta, expresso o meu agradecimento pela paciência demonstrada na revisăo do texto original, o qual também foi beneficiado com as sugestōes de dois revisores do Bol. IGUSP.

\section{REFERÊNCIAS BIBLIOGRÁFICAS}

ADAMS, S.S. (1985) Mineral Deposit Modeling in Exploration, In: International Workshop on Gold Deposit Modeling in Exploration, Golden, USA, 38p (draft copy).

AGTERBERG, F.P. (1981) Computers as an aid in mineral resource evaluation. In: MERRIAN, D.F.(ed.), Computer Applications in the Earth Sciences. New York, Plenum Press. p.43-61.

ALBERT, T.; HRUSKA, J; RASSAM, G. (1989) International Inventory of Automated Databases in the Geosciences, United States, IUGS/COGEODATA/COGEODOC, 249p.

BARTON, P.B. (1986) Preface. In: COX, D.P. \& SINGER, D.A., Mineral Deposit Models, U.S.Geological Survey Bulletin, (1693) III-IV.

CABRAL Jr., M. (1991) Avaliaçấ do Potencial Metalogenético da Bacia do Paraná no Estado de São Paulo para Depósitos Sedimentares Fosfáticos, Evaporíticos e de Metais Base. Rio Claro, 238p. (Dissertaçáo de Mestrado - Instituto de Geociências/UNESP).

CHIODI F, C. (1984) Contribuiçăo à geologia das regiōes Sul Paulista e Leste Paranaense Grupos Açungui e Setuva. In: CONGRESSO BRASILEIRO DE GEOLOGIA, 33., Rio de Janeiro, 1984. Anais. Rio de Janeiro, SBG. v.5, p.2394-2406.

COX, D.P.; BARTON, P.B.; SINGER, DA. (1986) Introduction. U.S.Geological Survey Bulletin, (1693): 1-10.

COX, D.P. \& SINGER, D.A. (1986) Mineral Deposit Models, U.S.Geological Survey Bulletin, (1693):1-379. 
CHUNG, C.F.; JEFFERSON, C.W.; SINGER, D.A. (1992) A quantitative link among mineral deposit modeling, geoscience mapping and exploration-resource assessment. Economic Geology, 87(1):194-197.

DAITX, E.C.; TAKAHASHI, A.T.; FERREIRA, J.C.G.; SILVA, C.R.; MAEYAMA, O. (1983) Projeto anta-gorda, Fase III, mapeamento geológico da área norte. São Paulo, DNPM/CPRM. 1 v.

ECKSTRAND, O.R. (1984) Canadian mineral deposit types: A geologic synopsis. Economic Geology Report - Geological Survey of Canada, (36):1-248.

ERICKSON, R.L. (1982) Characteristics of mineral deposit occurrences. U.S. Geological Survey Open File Report, 82-795:1-248.

FLEISCHER, R. (1976) A pesquisa de chumbo no Brasil. In: CONGRESSO BRASILEIRO DE GEOLOGIA, 29., Ouro Preto, 1976, Anais. Ouro Preto, SBG. v. 1, p.19-32.

GÁAL, G. (1984) Evaluation of the mineral resource potential of central Finnish Lapland by statistical analysis of geological, geochemical and geophysical data. Report of Investigation. Geological Survey of Finland, (63):1-69.

GÁAL, G. \& MERRIAN, D.S. (1990) Computer applications in resource estimation: prediction and assessment for metal and petroleum. Computers and Geology, (7):1-453.

HARRIS, D.P. (1984) Mineral resources appraisal, mineral endowment, resources and potential supply: concepts, methods and cases. Oxford, Clarendon. 445p. (Oxford Geological Sciences Series).

LADEIRA, E.A. (1980) Metallogenesis of gold at the Morro Velho mine and in the Nova Lima district, Quadrilatero Ferrifero, Minas Gerais, Brazil. Ontário, 272p. (These Doctoral University of Western Ontario, Canada).

MACEDO, A.B. (1986) Prospeçăo Litogeoquímica na Mina de Perau, Paraná. São Paulo, 162. (Tese de Foutorado - Instituto de Geociências/USP).

MERRIAN, D.F. (1981). Computer Applications in the Earth Sciences. New York, Plenum Press. 385p.

ROIG, H.L. (1990) Caracterização tipológica dos depósitos de Pb-Zn do tipo Mississipi Valey: uma revisăo. Cadernos IG/UNICAMP, 1(1): 75-100. 
ROBERTS, D.E. \& HUDSON, G.R.T. (1983) The Olympic Dam Copper-Uranium-Gold deposit, Roxby Downs, South Australia. Economic Geology, 78(4):799-822.

ROBERTS, R.G. \& SHEAHAN, P.A. (s.d.) Ore Deposit Models. Geoscience Canada, Reprint Series, (3):1-194.

SILVA, R.B. (1985) Considerações sobre os domínios metálicos de $\mathrm{Pb}, \mathrm{Zn}$ e F do Brasil. Revista do Instituto Geológico, 6(1/2):49-68.

SILVA, R.B.; MAEYAMA, O.; PEROSA, P.T.Y.; ALMEIDA, E.B.; SARAGIOTTO, J.A. (1982) Consideraçōes sobre as mineralizaçōes de chumbo, zinco e prata do Grupo Açungui no Estado de São Paulo. In: CONGRESSO BRASILEIRO DE GEOLOGLA, 32., Salvador, 1992. Anais. Salvador, SBG, v.3, p:972-986.

TASSINARI, C.C.G.; BARBOUR, A.P.; DAITX, E.C.; SATO, K. (1990) Aplicaçăo de isótopos de $\mathrm{Pb}$ e $\mathrm{Sr}$ na determinaçăo da natureza das fontes das mineralizaçōes de chumbo do Vale do Ribeira, SP e PR. In: CONGRESSO BRASILEIRO DE GEOLOGIA, 36., Natal, 1990. Anais. Natal, SBG. v.3, p.1254-1266.

USGS-INGEOMINAS (1984) Mineral Resource Assessment of Colombia, Open-File Report, (84-345):1-86.

WADGE,G. (1992) Geological applications of GIS. Journal Geological Society of London, 149:672. 